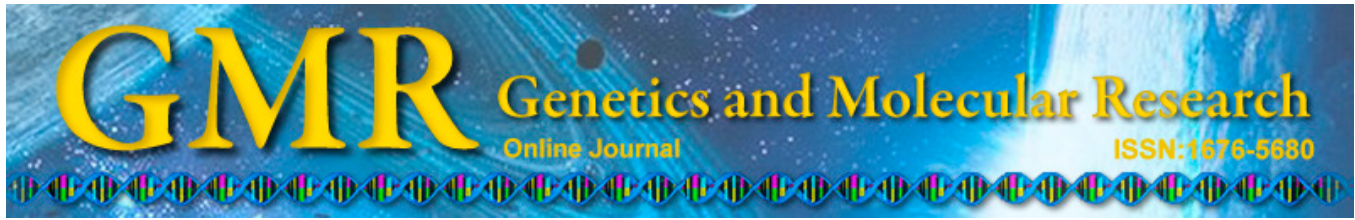

\title{
Polymorphisms of vascular endothelial growth factor on prognosis in hepatocellular carcinoma patients receiving transcatheter arterial chemoembolization treatment
}

\author{
J. Song, L.Z. Wang, X. Li, T.P. Jiang, T.Z. An, M. Xu, X.P. Wu and S. Zhou \\ Department of Radiology, Affiliated Hospital of Guiyang Medical College, \\ Guiyang, China \\ Corresponding author: S. Zhou \\ E-mail:wlz_wlz66@163.com \\ Genet. Mol. Res. 13 (4): 8946-8953 (2014) \\ Received September 17, 2013 \\ Accepted April 30, 2014 \\ Published October 31, 2014 \\ DOI http://dx.doi.org/10.4238/2014.October.31.9
}

\begin{abstract}
We conducted a cohort study to investigate the prognostic significance of vascular endothelial growth factor (VEGF) polymorphisms in hepatocellular carcinoma (HCC) patients after transcatheter arterial chemoembolization (TACE). In total, 156 patients with histologically confirmed HCC within 2 months were collected from January 2007 to January 2008. The genotypes of $V E G F-2578 \mathrm{C} / \mathrm{A}$, $-1154 \mathrm{G} / \mathrm{A},-634 \mathrm{C} / \mathrm{G}$, and $-1498 \mathrm{~T} / \mathrm{C}$ were determined from blood extracted using a blood kit on a 384-well plate. The survival rate at 5 years was $55.47 \%$. Multivariate analysis revealed that only tumornode-metastasis (TNM) stage, metastasis, and the $V E G F-2578$ AA and -1154 AA genotypes were independent prognostic factors. Patients with TNM stage III-IV and metastasis showed a greatly increased risk of death from HCC, with hazard ratios (HRs) [95\% confidence interval (CI)] of 3.64 (1.67-6.79) and 2.91 (1.30-6.27), respectively. Moreover, the VEGF-2578 AA and -1154 AA genotypes showed a significantly increased risk of death compared with the wild-type genotype (HR
\end{abstract}


$=3.65,95 \% \mathrm{CI}=1.35-11.13 ; \mathrm{HR}=7.13,95 \% \mathrm{CI}=1.46-65.8)$. These results will be helpful for predicting clinical outcomes of HCC patients.

Key words: Clinical outcome; Hepatocellular carcinoma; Polymorphism; Vascular endothelial growth factor

\section{INTRODUCTION}

Hepatocellular carcinoma (HCC) is the 5th most common cancer worldwide, and has the 4th highest mortality rate (IARC, 2008). Most of the burden is in developing countries, where nearly $85 \%$ of cases occur in men (IARC, 2008). In China, HCC was the 3rd most common malignancy, with approximately 292,966 new cancer cases in 2008 (IARC, 2008). Although methods for diagnosing HCC have improved, the prognosis of HCC remains poor. It is estimated that the 5-year overall survival (OS) rate of HCC is $26-44 \%$ after HCC resection (Wu et al., 2013a). Surgical resection and liver transplantation is the primary modality for managing early-stage disease, but most patients develop local or distant recurrence after diagnosis. However, only $10-30 \%$ of these patients are suitable candidates for surgery due to multicentricity or poor hepatic functional reserve. Currently, transarterial chemoembolization (TACE) or transarterial embolization is used as a standard palliative treatment for HCC (Bruix et al., 2004; Lewandowski et al., 2010; Bruix and Sherman, 2011).

TACE is used to exploit the arterial hypervascularization of HCC to obtain blood from newly formed arteries, in which occlusion and embolization with an emulsion of chemotherapeutic drugs and lipiodol together with embolizing agents, such as gelfoam, induce tumor necrosis (Sergio et al., 2008). TACE is used for small inoperable tumors that are not amenable to percutaneous treatments in patients with 1 nodule more than $5 \mathrm{~cm}$ in size, Child-Pugh class A or B, or multifocal HCC, and as a neoadjuvant therapy before radical treatments, such as orthotopic liver transplantation or hepatic resection (Bruix et al., 2004).

The OS of HCC patients receiving TACE remains unsatisfactory because the treated tumor frequently maintains residual viability, leading to disease reactivation; however, the survival rate is better for patients properly selected under standardized conditions (Farinati et al., 1996). Therefore, biological markers for predicting HCC reactivation and facilitating disease management must be identified. Vascular endothelial growth factor (VEGF), VEGF receptor-1 (VEGFR-1), and VEGF receptor-2 (VEGFR-2) are strong angiogenesis factors in HCC (Li et al., 1998), play important roles in the development and prognosis of HCC, and correlate with vascular invasion and metastasis (Itoh et al., 2000; Meng and Chen, 2002). However, few studies have been conducted to investigate the role of $V E G F$ polymorphisms in the prognosis of HCC patients receiving TACE treatment. Therefore, we conducted this cohort study to investigate the prognostic significance of $V E G F$ polymorphisms in HCC patients after TACE.

\section{MATERIAL AND METHODS}

\section{Subjects}

A total of 156 patients with $\mathrm{HCC}$ who were histologically confirmed within 2 months 
were collected from January 2007 to January 2008 at the Affiliated Hospital of Guiyang Medical College of China. HCC was diagnosed by liver biopsy or the combination of increased alpha-fetoprotein (AFP, $\geq 200 \mathrm{ng} / \mathrm{mL}$ ) and the typical vascular pattern on angiography or dynamic imaging. Clinical information, such as tumor differentiation, tumor size, Child-Pugh class, and surgery types were collected from medical records with patients' consent. All patients in our study received TACE treatment as an initial treatment for unresectable HCC and did not receive any other therapy. In addition, no HCC patients had extrahepatic metastasis to lymph nodes and/or other organs or any treatment prior to the present TACE. After screening, 156 patients were enrolled in our study, and 10 patients were excluded due to incomplete investigation or loss to follow-up due to migration. A total of 146 patients were followed up until the end of March 2012.

\section{Follow-up}

Patients were followed up every 2 months after inclusion into our study. All patient deaths were defined as the end point irrespective of cause of death. OS was calculated from the date of diagnosis to the date of death or the date of last follow-up. During the follow-up period, a total of 65 patients died (44.5\%). The median follow-up time was 34.6 months.

\section{TACE procedure}

The TACE procedure consisted of femoral arterial puncture into the celiac artery and hepatic artery to angiography. The location and size of tumor and site of feeding artery were identified. Chemoembolization was conducted with 2-3 chemotherapeutic regimens of 5 -fluorouracil, cisplatin or carboplatin, and mitomycin into segmental or subsegmental tumorfeeding arteries.

\section{Blood samples and genotyping}

All subjects provided $5 \mathrm{~mL}$ venous blood; blood samples were stored at $-20^{\circ} \mathrm{C}$ until use, with $0.5 \mathrm{mg} / \mathrm{mL}$ ethylenediamine tetraacetic acid added as an anticoagulant. Genomic DNA was extracted using the TIANamp blood DNA kit (Tiangen Biotech; Beijing, China) according to manufacturer instructions. VEGF -2578C/A, $-1154 \mathrm{G} / \mathrm{A},-634 \mathrm{C} / \mathrm{G}$, and $-1498 \mathrm{~T} / \mathrm{C}$ was extracted using the Qiagen Blood Kit (Qiagen; Hilden, Germany) and genotyping was conducted on a 384-well plate format on the MassARRAY platform (Sequenom; San Diego, CA, USA). The primers and probes of $V E G F-2578 \mathrm{C} / \mathrm{A},-1154 \mathrm{G} / \mathrm{A},-634 \mathrm{C} / \mathrm{G}$, and $-1498 \mathrm{~T} / \mathrm{C}$ were designed using the Sequenom Assay Design 3.1 software (Sequenom). The polymerase chain reaction (PCR) was conducted using $5 \mathrm{ng}$ genomic DNA in a $5-\mathrm{mL}$ reaction in the GeneAmp PCR System 9700 with Dual 384-Well Sample Block Module (Applied Biosystems; Foster City, CA, USA). PCR amplifications were conducted with 1-15 ng DNA from all serum samples using 1.0 U/mL HotStar Taq DNA polymerase (Qiagen), $0.21 \mathrm{M}$ forward and reverse primers, and $0.125 \mathrm{mM}$ dNTP. The amplification protocol was $95^{\circ} \mathrm{C}$ for $15 \mathrm{~min}$, followed by 35 cycles at $94^{\circ} \mathrm{C}$ for $1 \mathrm{~min}, 55^{\circ} \mathrm{C}$ for $1 \mathrm{~min}$, and $72^{\circ} \mathrm{C}$ for $1 \mathrm{~min}$ for 49 cycles, with a final extension step at $72^{\circ} \mathrm{C}$ for $10 \mathrm{~min}$. Reproducibility was verified by repeat analysis of a randomly chosen subgroup of $10 \%$ of the subjects. 


\section{Statistical analysis}

All analyses were performed using the SPSS version 16.0 statistical software (SPSS; Chicago, IL, USA). Continuous variables are reported as means \pm standard deviation, whereas categorical variables are shown as frequencies and percentages. Demographic characteristics were compared between cases and controls with the $\chi^{2}$ and Student $t$-tests. Survival distributions were estimated using the Kaplan-Meier method. The association between genotype and survival was estimated using hazard ratios (HRs) and their confidence intervals (CIs) from the multivariate Cox proportional hazards model. Two-sided $\mathrm{P}<0.05$ was considered to be significant.

\section{RESULTS}

\section{Patient characteristics}

Of the $156 \mathrm{HCC}$ patients screened for eligibility, 146 met the eligibility criteria and agreed to participate in the study, giving a participation rate of $93.5 \%$. Of the 146 HCC patients, $104(71.23 \%)$ were male and $42(28.77 \%)$ were female. The average age was $55.8 \pm 10.6$ years (range 24-81 years) (Table 1). Cumulative survival rates for all patients according to age, gender, viral infection, live cirrhosis, tumor-node-metastasis (TNM) stage, Child-Pugh classification, metastasis, tumor size, number of tumors, AFP levels, and vessel invasion are listed in Table 1.

Overall, the survival rate of patients at 5 years was $55.47 \%$. Both HBsAg-positive and anti-HCV Ab-positive patients showed the lowest survival rate at 5 years, and both negative groups showed a survival rate at 5 years of $73.08 \%$. The survival rates of patients in TNM stage I-II was significantly higher when compared with stage III-IV patients ( $\mathrm{P}=$ 0.037). Similarly, patients without metastasis and/or tumor size $<5 \mathrm{~cm}$ showed higher survival rates than those with metastasis and/or larger tumor sizes ( $\mathrm{P}$ values were 0.039 and 0.027, respectively).

A univariate Cox proportional hazards model was used to assess the survival of HCC patients that received TACE. Univariate analysis revealed that viral infection, TNM stage, metastasis, tumor size, and $V E G F-2578 \mathrm{C} / \mathrm{A}$ and $-1154 \mathrm{G} / \mathrm{A}$ increased the risk of death from HCC (Table 2). The HR of each variable ranged from 2.31 to 3.84 (Table 2). HBsAgpositive $\mathrm{HCC}$ patients showed a significantly increased risk of death $(\mathrm{HR}=2.57,95 \% \mathrm{CI}=$ 1.03-6.17). Patients with TNM stage III-IV of HCC showed an increased risk of death from HCC when compared with TNM stage I-II $(\mathrm{HR}=3.07,95 \% \mathrm{CI}=1.36-6.47)$. HCC patients with metastasis had a 3.13-fold increased risk of death compared with those without metastasis, and those with tumor size $\geq 5 \mathrm{~cm}$ had a 2.31 -fold increased risk of death compared with patients with smaller tumors. For the VEGF polymorphisms, we found that patients with the $V E G F-2578$ AA and -1154 AA genotypes had a 3.40- and 8.41-fold increased risk of HCC, respectively, compared to patients with the wild-type genotype.

Multivariate analysis revealed that only TNM stage, metastasis, and VEGF-2578 AA and -1154 AA genotypes were independent prognostic factors (Table 3). Patients with TNM stage III-IV and metastasis had a substantially increased risk of death from HCC, with 
HRs (95\%CI) of 3.64 (1.67-6.79) and 2.91 (1.30-6.27), respectively. Moreover, those with $V E G F-2578$ AA and -1154 AA genotypes showed a significantly increased risk of death compared to patients with the wild-type genotype $(\mathrm{HR}=3.65,95 \% \mathrm{CI}=1.35-11.13 ; \mathrm{HR}=$ $7.13,95 \% \mathrm{CI}=1.46-65.8)$.

\begin{tabular}{|c|c|c|c|c|c|c|}
\hline Variables & Cases $(\mathrm{N}=146)$ & $\%$ & Death $(\mathrm{N}=65)$ & $\%$ & Survival rate & $\mathrm{P}$ value \\
\hline Age (year, means \pm SD) & $55.8 \pm 10.6$ & & & & & \\
\hline \multicolumn{7}{|l|}{ Gender } \\
\hline Male & 104 & 71.23 & 48 & 73.85 & 53.85 & \\
\hline Female & 42 & 28.77 & 17 & 26.15 & 59.52 & 0.53 \\
\hline \multicolumn{7}{|l|}{ Viral infection } \\
\hline Both negative & 26 & 17.81 & 7 & 10.77 & 73.08 & \\
\hline HBsAg-positive & 87 & 59.59 & 40 & 61.54 & 54.02 & \\
\hline Anti-HCV Ab-positive & 28 & 19.18 & 15 & 23.08 & 46.43 & \\
\hline Both positive & 5 & 3.42 & 3 & 4.62 & 40.00 & 0.19 \\
\hline \multicolumn{7}{|l|}{ Liver cirrhosis } \\
\hline Absent & 39 & 26.71 & 19 & 29.23 & 51.28 & \\
\hline Present & 107 & 73.29 & 46 & 70.77 & 57.01 & 0.54 \\
\hline \multicolumn{7}{|l|}{ TNM stage } \\
\hline I-II & 60 & 41.10 & 17 & 26.15 & 71.67 & \\
\hline III-IV & 86 & 58.90 & 48 & 73.85 & 44.19 & 0.037 \\
\hline \multicolumn{7}{|l|}{ Child-Pugh classification } \\
\hline A & 43 & 29.45 & 17 & 26.15 & 60.47 & \\
\hline B & 62 & 42.47 & 27 & 41.54 & 56.45 & \\
\hline $\mathrm{C}$ & 41 & 28.08 & 21 & 32.31 & 48.78 & 0.55 \\
\hline \multicolumn{7}{|l|}{ Metastasis } \\
\hline No & 95 & 65.07 & 33 & 50.77 & 65.63 & \\
\hline Yes & 51 & 34.93 & 32 & 49.23 & 36.00 & 0.039 \\
\hline \multicolumn{7}{|l|}{ Tumor size } \\
\hline$<5 \mathrm{~cm}$ & 93 & 63.70 & 35 & 53.85 & 62.37 & \\
\hline$\geq 5 \mathrm{~cm}$ & 53 & 36.30 & 30 & 46.15 & 43.40 & 0.027 \\
\hline \multicolumn{7}{|l|}{ Number of tumors } \\
\hline 1 & 87 & 59.59 & 31 & 47.69 & 64.37 & \\
\hline$\geq 2$ & 59 & 40.41 & 34 & 52.31 & 42.37 & 0.108 \\
\hline \multicolumn{7}{|l|}{$\mathrm{AFP}(\mathrm{ng} / \mathrm{mL})$} \\
\hline$<200$ & 54 & 34.62 & 20 & 30.77 & 64.91 & \\
\hline$\geq 200$ & 92 & 65.38 & 45 & 69.23 & 49.44 & 0.25 \\
\hline \multicolumn{7}{|l|}{$V E G F$ polymorphism } \\
\hline \multicolumn{7}{|l|}{$-2578 \mathrm{C} / \mathrm{A}$} \\
\hline $\mathrm{CC}$ & 64 & 43.84 & 23 & 35.38 & 64.06 & \\
\hline $\mathrm{CA}$ & 50 & 34.25 & 21 & 32.31 & 58.00 & \\
\hline AA & 32 & 21.92 & 21 & 32.31 & 34.38 & 0.25 \\
\hline \multicolumn{7}{|l|}{$-1154 \mathrm{G} / \mathrm{A}$} \\
\hline GG & 86 & 58.90 & 34 & 52.31 & 60.47 & \\
\hline GA & 47 & 32.19 & 20 & 30.77 & 57.45 & \\
\hline AA & 13 & 8.90 & 11 & 16.92 & 15.38 & 0.23 \\
\hline \multicolumn{7}{|l|}{$-634 \mathrm{C} / \mathrm{G}$} \\
\hline $\mathrm{CC}$ & 66 & 45.21 & 28 & 43.08 & 57.58 & \\
\hline CG & 55 & 37.67 & 25 & 38.46 & 54.55 & \\
\hline GG & 25 & 17.12 & 12 & 18.46 & 52.00 & 0.88 \\
\hline \multicolumn{7}{|l|}{$-1498 \mathrm{~T} / \mathrm{C}$} \\
\hline TT & 69 & 47.26 & 28 & 43.08 & 59.42 & \\
\hline $\mathrm{TC}$ & 60 & 41.10 & 28 & 43.08 & 53.33 & \\
\hline $\mathrm{CC}$ & 16 & 10.96 & 9 & 13.85 & 43.75 & 0.49 \\
\hline
\end{tabular}




\begin{tabular}{|c|c|c|c|c|}
\hline Variables & Median survival (95\%CI, months) & Log-rank P & $\mathrm{HR}(95 \% \mathrm{CI})^{1}$ & $P$ value \\
\hline \multicolumn{5}{|l|}{ Viral infection } \\
\hline Both negative & $37.8 \pm 7.4$ & & 1.0 (Ref.) & \\
\hline HBsAg-positive & $30.4 \pm 8.2$ & 0.07 & $2.57(1.03-6.17)$ & 0.03 \\
\hline Anti-HCV Ab-positive & $31.7 \pm 7.7$ & 0.06 & $3.07(0.82-10.92)$ & 0.05 \\
\hline Both positive & $29.4 \pm 8.9$ & 0.12 & $3.84(0.34-51.63)$ & 0.15 \\
\hline \multicolumn{5}{|l|}{ TNM stage } \\
\hline I-II & $36.4 \pm 8.8$ & & 1.0 (Ref.) & \\
\hline III-IV & $30.7 \pm 9.2$ & 0.001 & $3.07(1.36-6.47)$ & $<0.001$ \\
\hline \multicolumn{5}{|l|}{ Metastasis } \\
\hline No & $37.7 \pm 7.4$ & & 1.0 (Ref.) & \\
\hline Yes & $32.5 \pm 8.3$ & 0.002 & $3.13(1.40-6.55)$ & 0.002 \\
\hline \multicolumn{5}{|l|}{ Tumor size } \\
\hline$<5 \mathrm{~cm}$ & $33.6 \pm 7.4$ & & 1.0 (Ref.) & \\
\hline$\geq 5 \mathrm{~cm}$ & $35.8 \pm 8.3$ & 0.015 & $2.31(1.04-4.75)$ & 0.023 \\
\hline \multicolumn{5}{|l|}{$V E G F$ polymorphism } \\
\hline \multicolumn{5}{|l|}{$-2578 \mathrm{C} / \mathrm{A}$} \\
\hline $\mathrm{CC}$ & $37.8 \pm 8.1$ & & 1.0 (Ref.) & \\
\hline $\mathrm{CA}$ & $31.1 \pm 7.9$ & & $1.29(0.56-2.95)$ & 0.51 \\
\hline AA & $27.8 \pm 8.5$ & 0.004 & $3.40(1.28-9.20)$ & 0.006 \\
\hline \multicolumn{5}{|l|}{$-1154 \mathrm{G} / \mathrm{A}$} \\
\hline GG & $38.4 \pm 6.5$ & & 1.0 (Ref.) & \\
\hline $\mathrm{GA}$ & $32.5 \pm 8.1$ & & $1.13(0.51-2.48)$ & 0.73 \\
\hline AA & $28.4 \pm 8.2$ & 0.007 & $8.41(1.65-81.1)$ & 0.002 \\
\hline
\end{tabular}

${ }^{1}$ Adjusted for gender, age, viral infection, and metastasis.

Table 3. Multivariate analysis of factors affecting survival of HCC patients.

\begin{tabular}{lcc}
\hline Variables & HR $(95 \% \mathrm{CI})^{1}$ & P value \\
\hline TNM stage & 1.0 (Ref.) & \\
I-II & $3.64(1.67-6.79)$ & 0.006 \\
III-IV & 1.0 (Ref.) & \\
Metastasis & $2.91(1.30-6.27)$ & 0.003 \\
No & & \\
Yes & 1.0 (Ref.) & 0.24 \\
VEGFR-2 (ng/L) & $1.37(0.47-3.16)$ & $<0.001$ \\
-2578C/A & $3.65(1.35-11.13)$ & \\
CC & 1.0 (Ref.) & 0.47 \\
CA & $1.25(0.63-2.78)$ & $<0.001$ \\
AA & $7.13(1.46-65.8)$ & \\
-1154G/A & & \\
GG & & \\
GA & & \\
AA &
\end{tabular}

${ }^{1}$ Adjusted for gender, age, viral infection, and metastasis.

\section{DISCUSSION}

Genetic factors can affect the development of HCC, which in turn can play an important role in the incidence rate or progression of carcinoma. Genes implicated in angiogenesis may be indicators of the progression and important prognostic factors in various cancers, such as pancreatic, gastric, lung, and renal cell cancer (Sáenz-López et al., 2013; Sivaprasad et al., 2013; Oh et al., 2013; Sun et al., 2013). VEGF, a growth factor that regulates angiogenesis, is regarded to be the most potent stimulatory cytokine regulating tumor angiogenesis and an important factor in metastasis, survival, and tumor spread (Salven et al., 1997). Several polymorphisms in the $V E G F$ gene have been recently identified, and $-2578 \mathrm{C} / \mathrm{A}$ and $-1154 \mathrm{G} / \mathrm{A}$ in 
the promoter region of $V E G F$ may play a role in altering gene transcription and expression (Absenger et al., 2013; Oh et al., 2013). In this study, we found that the VEGF-2578C/A and $-1154 \mathrm{G} / \mathrm{A}$ polymorphisms were correlated with tumor stage and tumor size, and were associated with shorter survival time of HCC patients.

The $V E G F$ gene is located on chromosome 6p21.3 and consists of 8 exons. It is estimated that there are more than 30 single-nucleotide polymorphisms (SNPs) in $V E G F$. DNA sequence variations in the $V E G F$ gene may alter VEGF production and/or activity, thereby causing interindividual differences in susceptibility to lung cancer because of their effects on tumor angiogenesis pathways. VEGF polymorphisms have been studied in relation to risk and histopathological characteristics of various cancers with disparate results (Koukourakis et al., 2004; Chien et al., 2013; Luo et al., 2013; Oh et al., 2013; Sa-Nguanraksa et al., 2013; Wu et al., 2013b). Four common SNPs, -2578C/A, -1154G/A, -634C/G, and -1498T/C, have been reported to be significantly associated with VEGF protein production (Koukourakis et al., 2004; Oh et al., 2013). In addition, these 4 SNPs play a role in the risk or prognosis of various diseases, such as breast cancer, pancreatic adenocarcinoma, oral cancer, hepatocellular cancer, non-small cell lung cancer, and gastric cancer (Koukourakis et al., 2004; Chien et al., 2013; Oh et al., 2013; Wu et al., 2013b). Our results suggest that the $V E G F-2578 \mathrm{C} / \mathrm{A}$ and $-1154 \mathrm{G} / \mathrm{A}$ polymorphisms do not play a major role in the carcinogenesis of HCC. The $V E G F-2578 \mathrm{C} / \mathrm{A}$ and $-1154 \mathrm{G} / \mathrm{A}$ polymorphisms have been associated with decreased risk and aggressiveness of certain cancers (Tamura et al., 2012; Sa-Nguanraksa et al., 2013), showing conflicting results to those of our study. This finding is biologically plausible, particularly in light of the putative function of these polymorphisms.

There were several limitations in our study. First, cases were selected from one hospital, which may not be representative of the general population. Second, other genetic polymorphisms may influence the prognosis of HCC besides the VEGF gene. Therefore, further large sample, multicenter studies including different ethnicities are warranted to investigate the role of $V E G F$ gene polymorphisms on the prognosis of HCC.

In conclusion, we found that the $V E G F-2578 \mathrm{C} / \mathrm{A}$ and $-1154 \mathrm{G} / \mathrm{A}$ polymorphisms may affect the prognosis of $\mathrm{HCC}$ patients. Our finding suggests that the $V E G F-2578 \mathrm{C} / \mathrm{A}$ and $-1154 \mathrm{G} / \mathrm{A}$ polymorphisms alter VEGF expression. These finding may be useful for predicting the clinical outcome of patients with HCC. Further studies are needed to confirm the clinical significance of these results.

\section{REFERENCES}

Absenger G, Szkandera J, Stotz M, Pichler M, et al. (2013). A common and functional gene variant in the vascular endothelial growth factor predicts a clinical outcome in early-stage breast cancer. Mol. Carcinog. 52 (Suppl 1): E96-102.

Bruix J and Sherman M (2011). Management of hepatocellular carcinoma: an update. Hepatology 53: 1020-1022.

Bruix J, Sala M and Llovet JM (2004). Chemoembolization for hepatocellular carcinoma. Gastroenterology 127: S179-S188.

Chien MH, Liu YF, Hsin CH, Lin CH, et al. (2013). Impact of VEGF-C gene polymorphisms and environmental factors on oral cancer susceptibility in Taiwan. PLoS One 8: e60283.

Farinati F, De Maria N, Marafin C, Herszenyi L, et al. (1996). Unresectable hepatocellular carcinoma in cirrhosis: survival, prognostic factors, and unexpected side effects after transcatheter arterial chemoembolization. Dig. Dis. Sci. 41: 2332-2339.

International Agency for Research on Cancer (IARC) (2008). Lung Cancer Incidence, Mortality and Prevalence Worldwide in 2008. Avalaible at [http://globocan.iarc.fr/]. Accessed January 10, 2013. 
Itoh T, Hayashi Y, Kanamaru T, Morita Y, et al. (2000). Clinical significance of urokinase-type plasminogen activator activity in hepatocellular carcinoma. J. Gastroenterol. Hepatol. 15: 422-430.

Koukourakis MI, Papazoglou D, Giatromanolaki A, Bougioukas G, et al. (2004). VEGF gene sequence variation defines VEGF gene expression status and angiogenic activity in non-small cell lung cancer. Lung Cancer 46: 293-298.

Lewandowski RJ, Mulcahy MF, Kulik LM, Riaz A, et al. (2010). Chemoembolization for hepatocellular carcinoma: comprehensive imaging and survival analysis in a 172-patient cohort. Radiology 255: 955-965.

Li XM, Tang ZY, Zhou G, Lui YK, et al. (1998). Significance of vascular endothelial growth factor mRNA expression in invasion and metastasis of hepatocellular carcinoma. J. Exp. Clin. Cancer Res. 17: 13-17.

Luo T, Chen L, He P, Hu QC, et al. (2013). Vascular endothelial growth factor (VEGF) gene polymorphisms and breast cancer risk in a Chinese population. Asian Pac. J. Cancer Prev. 14: 2433-2437.

Meng C and Chen X (2002). Association of VEGF, uPA, ICAM-1 and PCNA expression with metastasis and recurrence in hepato cellular carcinoma. Zhonghua Wai Ke Za Zhi 40: 673-675.

Oh SY, Kwon HC, Kim SH, Lee S, et al. (2013). The relationship of vascular endothelial growth factor gene polymorphisms and clinical outcome in advanced gastric cancer patients treated with FOLFOX: VEGF polymorphism in gastric cancer. BMC Cancer 13: 43.

Sa-Nguanraksa D, Chuangsuwanich T, Pongpruttipan T, Kummalue T, et al. (2013). Vascular endothelial growth factor $634 \mathrm{G} / \mathrm{C}$ polymorphism is associated with increased breast cancer risk and aggressiveness. Mol. Med. Rep. 8: 1242-1250.

Sáenz-López P, Vazquez F, Cozar JM, Carretero R, et al. (2013). VEGF polymorphisms are not associated with an increased risk of developing renal cell carcinoma in Spanish population. Hum. Immunol. 74: 98-103.

Salven P, Teerenhovi L and Joensuu H (1997). A high pretreatment serum vascular endothelial growth factor concentration is associated with poor outcome in non-Hodgkin's lymphoma. Blood 90: 3167-3172.

Sergio A, Cristofori C, Cardin R, Pivetta G, et al. (2008). Transcatheter arterial chemoembolization (TACE) in hepatocellular carcinoma (HCC): the role of angiogenesis and invasiveness. Am. J. Gastroenterol. 103: 914-921.

Sivaprasad S, Govardhan B, Harithakrishna R, Venkat RG, et al. (2013). Association of vascular endothelial growth factor (VEGF) gene polymorphism and increased serum VEGF concentration with pancreatic adenocarcinoma. Pancreatology 13: 267-272.

Sun SF, Huang DB, Cao C and Deng ZC (2013). Polymorphism of VEGF-460C/T associated with the risk and clinical characteristics of lung cancer in Chinese population. Med. Oncol. 30: 410.

Tamura T, Kuwahara A, Yamamori M, Nishiguchi K, et al. (2012). VEGF -634C/G genotype is predictive of long-term survival after treatment with a definitive 5-fluorouracil/cisplatin-based chemoradiotherapy in Japanese patients with esophageal squamous cell carcinoma. Int. J. Med. Sci. 9: 833-837.

Wu KT, Wang CC, Lu LG, Zhang WD, et al. (2013a). Hepatocellular carcinoma: clinical study of long-term survival and choice of treatment modalities. World J. Gastroenterol. 19: 3649-3657.

Wu X, Xin Z, Zhang W, Wu J, et al. (2013b). Polymorphisms in the VEGFA promoter are associated with susceptibility to hepatocellular carcinoma by altering promoter activity. Int. J. Cancer 133: 1085-1093. 